\title{
Assessing food insecurity prevalence and associated factors among college students enrolled in a university in the Southeast USA
}

\author{
Ruth Wooten, Marsha Spence, Sarah Colby and Elizabeth Anderson Steeves* \\ Department of Nutrition, University of Tennessee, Knoxville, 1215 W. Cumberland Avenue, 229 Jessie Harris \\ Building, Knoxville, TN 37996, USA
}

Submitted 27 June 2018: Final revision received 30 September 2018: Accepted 30 October 2018: First published online 21 December 2018

\begin{abstract}
Objective: To assess rates of food insecurity (FI) among college students enrolled at a large public university system across one US state and identify factors associated with experiencing FI.

Design: Cross-sectional online survey administered to eligible, enrolled students ( $n$ 38614) across three campuses within the university system, with 5593 students responding (4824 final sample after applying exclusion criteria, $12.5 \%$ response rate). FI was assessed using the US Department of Agriculture's Adult Food Security Survey Module. Descriptive statistics were conducted to calculate FI status and identify sample characteristics. Associations between FI status and independent variables were assessed using bivariate analyses ( $\chi^{2}$ and ANOVA tests) and multivariate logistic regression.

Setting: Large public university system, Southeast USA.

Participants: Enrolled college students (excluding freshman, <18 years of age).

Results: Thirty-six per cent of students were classified as FI. After controlling for confounders, factors that were significantly associated with increased likelihood of FI included previous FI $(P<0.001 ;$ OR $=4.78)$, financial factors and selfreported grade point average $\leq 3 \cdot 85$. Seniors were significantly more likely experience FI than graduate students $(P=0.004$, OR $=1.41)$. A significant relationship was not identified between FI and meal plan participation, and no differences in FI were found between graduate students and individuals with sophomore or junior standing.

Conclusions: This research identifies high rates of FI among college students enrolled in a large public university system in the Southeast USA, as well as selected factors related to FI. Programmes to assist college students experiencing FI need to be developed and tested.
\end{abstract}

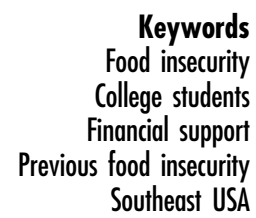

Keywords

Food insecurity

College students

food insecurity

Southeast USA
In 2016, approximately $12 \%$ of US households ( $41 \cdot 2$ million people) experienced food insecurity, or lack of consistent access to enough food for an active, healthy life ${ }^{(1)}$. Studies have found that food insecurity is related to increased likelihood of obesity ${ }^{(2,3)}$. Further, adults who experience food insecurity are at increased odds of stroke, arthritis, diabetes, chronic heart disease, hypertension and heart attack compared with their food-secure counterparts. The US Department of Agriculture (USDA) recommends that food insecurity be assessed among all populations as it is often considered 'a direct measure of well-being' and has many potential health consequences ${ }^{(4)}$. Research suggests that food-insecure adolescents and young adults are at high risk for diminished academic performance, less healthy dietary intake and poorer mental, social and overall health ${ }^{(5-7)}$.
Multiple factors associated with the college experience may make college students particularly vulnerable to food insecurity. When students transition to college, they may be faced with a new-found independence, financial burdens and stressors ${ }^{(8-10)}$. All or part of the responsibility of financial provision may fall upon the student. Annual increases in tuition costs may enhance these financial burdens and other factors like increased living costs or reliance on financial aid may also contribute to food insecurity in this population ${ }^{(11-13)}$.

In recent years, research studies have begun to assess prevalence of food insecurity among college students. In these studies, food insecurity prevalence among college students in the USA ranged from 14 to $59 \%^{(12-21)}$. A recent systematic review found that the average food 
insecurity rate among college students was $42 \%{ }^{(22)}$. These numbers are problematically high, but it is important to note that a wide variety of food insecurity assessment techniques were used in these studies, including the USDA ten-item Adult Food Security Survey Module (AFSSM) ${ }^{(12,13,16,18,20)}$, the eighteen-item USDA Household Food Security Survey Module (HFSSM) ${ }^{(21)}$, the six-item short form of the USDA $\operatorname{HFSSM}^{(15,17,19)}$, or brief one- to two-question instruments ${ }^{(14,23)}$, which may have contributed to the variability in findings.

In selected studies, financial-related factors, i.e. receiving financial aid or student loans ${ }^{(12,18,24)}$, familial financial support $^{(21)}$ or increased spending ${ }^{(16,20)}$, were significantly associated with prevalence of food insecurity. Students who received financial aid were at an increased risk of food insecurity ${ }^{(12,18,20)}$, while those who received familial financial support were at a decreased risk of food insecurity $^{(21)}$. Both generalized ${ }^{(20)}$ and specific categorical ${ }^{(16)}$ higher monetary expenditures, i.e. monthly spending and eating out or shopping, respectively, were associated with increased likelihood of food insecurity. While these significant relationships have been found, it is difficult to assess socio-economic factors in this population for several reasons. College students may have varying levels of financial dependence on their families. For example, students from higher socio-economic status backgrounds may spend less on essential expenses (housing, tuition, food) than students from lower socio-economic status backgrounds because of familial financial support that may cover the expenses. In addition, these socio-economic factors are highly linked; thus, efforts to appropriately assess specific financial factors of interest may be challenging in a college population. One important financial factor that has been understudied to date is the relationship between experiencing food insecurity prior to college and experiencing food insecurity during college, which may be an essential factor to address the identified high rates of food insecurity. A college education may prove to beneficial to breaking out of a possible cycle of poverty; however, food insecurity may still persist as a factor to the cycle in the collegiate environment.

In addition to financial factors, several studies identified that students experiencing food insecurity were more likely to have lower grade point averages (GPA) ${ }^{(13,18-20)}$, potentially identifying a relationship that may hinder academic achievement. When comparing undergraduate and graduate students, studies at large, public universities identified a significantly increased likelihood of food insecurity among undergraduate students compared with graduate students ${ }^{(17,20)}$; however, these findings were not consistent across all studies ${ }^{(16)}$.

In 2014-2016, the general population in the Southeast USA had the highest rate of food insecurity (14\%) compared with other US regions (Midwest, 12\%; West, 12\%; Northeast, $11 \%)^{(1)}$; however, it is unknown if these higher regional rates are consistent among college populations. Currently, the two published studies at other large, public universities in the Southeast region found inconsistent rates of food insecurity, 14 and $46 \%$, respectively ${ }^{(12,20)}$. The potential negative impacts of food insecurity ${ }^{(7,13,16,18-20)}$, coupled with higher rates of food insecurity in the general population in the Southeast ${ }^{(1)}$ and inconsistencies in rates identified in previous research with Southeastern college populations, demonstrate the need to assess food insecurity prevalence among students at additional universities in the Southeast region. Further, more research is needed to confirm which factors increase the likelihood of experiencing food insecurity, particularly experiencing food insecurity before college, as this has been understudied to date. Food insecurity has been related to factors such as finances ${ }^{(12,16,18,19)}$ and $\mathrm{GPA}^{(13,18,19)}$ in several studies, and to factors such as housing ${ }^{(13,18)}$, employment ${ }^{(19)}$ and race $^{(13,18)}$ in a small number of studies. Additional analyses are needed to enhance our understanding of these important relationships. The present study aims to address these gaps in the literature by assessing the rates of food insecurity among college students enrolled in a large public university system in one state in the Southeast USA and identifying factors that increase the likelihood of experiencing food insecurity among students.

\section{Methods}

\section{Participants and recruitment}

Students enrolled at three campuses of a large university system in one state in the Southeast USA were recruited to participate in the study via a series of three emails. The emails were sent to all enrolled students (total $n 38614)^{(25)}$ through campus-wide systems at each school over three weeks in September-October 2017. The first email explained the online survey and invited students to participate via the web link, which was unique to each campus. The following two emails, sent one and two weeks after the first email, reminded students to take the survey and contained the web link ${ }^{(24)}$. The survey remained open for data collection for a total of four weeks ${ }^{(26)}$. Participation was incentivized by offering respondents an optional opportunity to take part in a draw for one of eight \$US 100 gift cards by entering their email in a separate form that was not linked to the survey. Participants who completed the survey who were not college students ( $n$ 5), did not complete the AFSSM ( $n$ 695) and were below the age of 18 years ( $n$ 51) were excluded from analysis, resulting in a final sample of 4842 . Since the AFSSM asks about food insecurity experiences in the last 12 months, freshmen were not eligible as their past 12 months were likely not spent in the college environment. Informed consent was provided on the first screen of the survey.

\section{Survey development}

The online survey was developed in partnership with a consortium of researchers from universities across the 
Southeast USA to assess food insecurity status among college students (http://www.hunger-research.sog.unc. edu/content/about). The survey collected information on food security status, academic standing/success, health status, and demographic and socio-economic indicators. Prior to implementation, pilot testing of the survey was completed with a sample of thirty-six students from two colleges in the Southeast region who were similar to the target population due to their geographic location in the Southeast and college enrolment. Students were asked to complete the survey via the web link and discuss the questions as a group with an emphasis on readability and relevance of the questions to a college population, as well as acceptability of survey delivery method. Feedback from nutrition and public health experts was sought to assess content validity in the adaptation of selected questions ${ }^{(27)}$. Survey questions were modified based upon their feedback prior to the start of data collection.

\section{Food security}

Food security status was assessed using the AFSSM, a tenitem questionnaire from the USDA that is considered the gold standard for assessing food security status among adults $^{(28)}$. This questionnaire focuses on experiences within the last 12 months with questions about anxiety related to food supply, experience of running out of food or money to buy food, inadequate food intake due to lack in either quantity or quality, and experiencing hunger or weight loss due to reduced food intake. The responses were coded based on established protocols ${ }^{(28)}$. Scored responses were summed on a scale of $0-10$, delineating the food security status category. A score of 0 was classified as high food security, and a score of 1-2 was marginal food security. Classification of food insecure included the low food security category (score of 3-5) and very low food security category (score of 6-10). For the purpose of the present analysis, the food security categories were dichotomized to food secure (high and marginal food security) and food insecure (low and very low food security).

In addition, students were asked about their food security status before coming to college through two questions adapted from a previously validated food security status screener ${ }^{(27)}$. The statements were as follows: 'Before I came to college, we (my parent/guardian and/or I) worried whether our food would run out before we had money to buy more' and 'Before I came to college, the food we (my parent/guardian and/or I) bought just didn't last and we didn't have money to get more'. Responses were 'often', 'sometimes' and 'never', with an affirmative response to either question indicating food insecurity status before attending college and a response of 'never' indicating no previous food insecurity. These adaptations were assessed and reviewed through content and face validation with experts in the field.
Demographics, academic factors and health-related factors

Four questions were used to collect demographic information from the students. The questions included gender, age, race and ethnicity. To collect information related to academic factors, students were asked to report their year in school ('sophomore', 'junior', 'senior', 'graduate', 'other') and identify as a part- or full-time student. Additionally, students were asked to self-report their GPA on a 4.0 scale. Similar to previous studies, the self-reported GPA variable was categorized using the following ranges to capture academic achievement levels '<3.00', '3.00-3.49', '3.50-3.84' and '3.85-4.00'. Students were asked to identify, 'yes' or 'no', if they participated in an on-campus meal plan.

\section{Socio-economic factors}

Students were asked to select any of following terms to best describe their income source: 'parent/family support', 'spouse/partner/significant other support', 'scholarship/grant (that you don't have to pay back)', 'private or federal loan (that you do have to pay back)', 'one or more part-time jobs', 'one full-time job', 'personal savings' and 'other.' This variable was dichotomous with either a 'yes' or 'no' response in each category. For the purpose of analysis, 'parent/family support' and 'spouse/ partner/significant other support' were combined to one variable, 'familial financial support'. Additionally, students were asked about their monthly expenditures from a set of questions adapted from the literature ${ }^{(16)}$. This included asking respondents to report their monthly expenditures on housing and cellular phones, groceries, eating out, shopping, transportation and entertainment. In addition, respondents were asked to report how much they spent on large one-time expenditures for the semester, e.g. tuition. Responses included various dollar amount categories, tailored to each expenditure item. For analysis, scores from housing, cell phone, groceries and transportation categories were summed to create an 'essential expenditures' category (mean $=7 \cdot 96, \mathrm{sD}=3 \cdot 90$, minimum $=0$, maximum $=19$, Cronbach's $\alpha=0 \cdot 68$ ). Scores from eating out, shopping and entertainment were summed to create a 'non-essential expenditures' category $($ mean $=4 \cdot 07, \mathrm{sD}=2 \cdot 44$, minimum $=0$, maximum $=15$, Cronbach's $\alpha=0 \cdot 72$ ).

\section{Statistical analyses}

Summary statistics were assessed to check for outliers and missing data. Outliers were evaluated to determine if they were errors in responses or true outliers. Responses deemed errors were dropped from the data set, while true outliers were retained, and sensitivity analyses were conducted to determine the impact of the outliers. Descriptive statistics were used to assess characteristics of the sample and food security status levels. Bivariate analyses were completed using $\chi^{2}$ tests and ANOVA tests to 
assess associations between the dependent variable of food security status and independent variables (food insecurity before college, familial financial support, parttime job, full-time job, personal savings, loans requiring repayment, participation in a meal plan, scholarships not requiring repayment, year in school, self-reported GPA, essential expenditures and non-essential expenditures). The variables that were significant in the bivariate analyses were included in the multivariate logistic regression model, including academic factors (self-reported GPA and year in school), participation in a meal plan and financial factors (income sources and monthly expenditures). Additionally, similar to the previous literature ${ }^{(13,16,19,23)}$, factors controlled for included age, race, ethnicity, gender and campus location. Students who had missing responses for the variables in the multivariable model were excluded from analysis ( $n$ 457). The missing responses were visually inspected and appeared to be missing at random ${ }^{(29)}$. The Hosmer-Lemeshow test was completed to assess goodness-of-fit; and assumptions of multivariate logistic regression (that the variables are independent, sample size is large and the dependent variable is binary) were checked ${ }^{(30)}$. Data were analysed using the statistical software package IBM SPSS Statistics for Windows version 24.0. Statistical significance for all tests was determined at $\alpha \leq 0.05$ level.

\section{Results}

Among eligible students ( $n$ 38614), 5593 responded to the survey. After applying the exclusion criteria mentioned above, the final sample size was 4842 (12.5\% response rate). As seen in Table 1 , the majority of students were undergraduates (72.0\%) and enrolled full-time (91.0\%). The mean self-reported GPA of students was 3.41 (SD 0.6), with $31.5 \%$ of respondents having a self-reported GPA between 3.50 and 3.84. The mean age of students was 23.6 years (SD 6.7) years. Most students identified as White (81.4\%), not Hispanic or Latino (95.3\%) and were female (70.1\%).

According to the scores from the AFSSM, $19 \cdot 5 \%$ of students were classified as very low food secure and $16 \cdot 1 \%$ as low food secure; taken together, 35.6\% of students were classified as food insecure. A total of $64.4 \%$ of students were classified as food secure with $42 \cdot 0 \%$ classified as high food secure and $22.4 \%$ as marginal food secure.

Chi-square analyses were used to assess associations of demographic, financial and academic variables with food security status (Table 2 ). Students who were food insecure before college $(P<0 \cdot 001)$, did not receive familial financial support $(P<0.001)$, had part-time or full-time jobs $(P<0 \cdot 001)$, relied on personal savings $(P=0 \cdot 001)$, received loans requiring repayment $(P<0 \cdot 001)$, participated in a meal plan $(P=0.001)$, received scholarships not requiring repayment $(P=0.021)$, were undergraduates $(P<0.001)$, had decreased non-essential expenditures $(P<0.001)$ and had increased essential expenditures $(P<0.001)$ were significantly more likely to be classified as food insecure.

Many of the variables included in the multivariate logistic regression were statistically significant (Table 3). The Hosmer-Lemeshow test indicated the model was a good fit $\left(\chi^{2}=4.70, P=0.789\right)$. While controlling for race, age, gender, ethnicity and holding all other variables in the model constant, previous food security status was the strongest correlate of food insecurity (OR $=4.78 ; 95 \% \mathrm{CI}$ $4.00,5 \cdot 71$ ), indicating that students with previous food insecurity were 4.78 times more likely to be food insecure than the students who did not experience food insecurity before college. Those who received a loan that had to be repaid were 1.42 times more likely to be food insecure compared with those who did not receive loans that had to be repaid (95\% CI 1.22, 1.66). Similarly, those who had not received familial financial support were 1.56 times more likely to be food insecure than those who had received familial financial support (95\% CI 1.33, 1.84). Students who had part-time jobs were 1.28 times more likely to be food insecure compared with those who did not have part time jobs (95\% CI 1.10, 1.50), while those without full-time jobs were 1.30 times more likely to be food insecure compared with those who had full-time jobs (95\% CI 1.00, 1.69). Additionally, students who used personal savings as an income source had an increased likelihood of food insecurity compared with those who did not $(\mathrm{OR}=1 \cdot 21 ; 95 \%$ CI 1.04, 1.40).

Related to student spending, the present analysis found that as essential expenditures increased, the likelihood of being food insecure also increased $(\mathrm{OR}=1.03$; CI 1.00, 1.05). Conversely, the likelihood of being food insecure decreased as non-essential expenditures increased $(\mathrm{OR}=0 \cdot 84$; CI 0.81, 0.87).

Students who were seniors were 1.41 times more likely to be food insecure than the reference group, graduate students (95\% CI 1.12, 1.79); however, there were no significant differences in odds of being food insecure between the reference group, graduate students, and other grade levels included in the analysis (juniors, sophomores). When compared with students with a self-reported GPA of 3.85-4.00, students with a self-reported GPA $<3.00$ were 2.85 times more likely to be food insecure (95\% CI $2 \cdot 23,3 \cdot 64)$, followed by those with a self-reported GPA of 3.00-3.49 (OR = 1.85; $95 \%$ CI $1.49,2 \cdot 29)$ and those with a self-reported GPA of 3.50-3.84 (OR=1.41; CI 95\% 1.15, 1.73). No significant associations were found between students who participated in a campus meal plan $v$. those who did not.

\section{Discussion}

Among the college students in the present sample, 35.6\% reported being food insecure, which was more than double the average rate $(13.4 \%)$ of the general population in the same state ${ }^{(1)}$ and similar to other studies ${ }^{(13,14,16-21)}$. 
Table 1 Participant demographics and characteristics of college students at a large public university system in the Southeast USA ( $n$ 4842) by food security status, 2017

\begin{tabular}{|c|c|c|c|c|c|c|c|c|c|c|c|c|}
\hline \multirow[b]{2}{*}{ Variable } & \multicolumn{2}{|c|}{$\begin{array}{c}\text { Total campus } \\
\text { population }^{\star}\end{array}$} & \multicolumn{2}{|c|}{ Total sample } & \multicolumn{2}{|c|}{$\begin{array}{l}\text { Very low food } \\
\text { security }\end{array}$} & \multicolumn{2}{|c|}{ Low food security } & \multicolumn{2}{|c|}{$\begin{array}{l}\text { Marginal food } \\
\text { security }\end{array}$} & \multicolumn{2}{|c|}{$\begin{array}{l}\text { High food } \\
\text { security }\end{array}$} \\
\hline & $n$ & Column \% & $\begin{array}{l}n \text { or } \\
\text { Mean }\end{array}$ & $\begin{array}{l}\text { Column } \\
\% \text { or SD }\end{array}$ & $\begin{array}{l}n \text { or } \\
\text { Mean }\end{array}$ & $\begin{array}{l}\text { Column } \\
\% \text { or SD }\end{array}$ & $\begin{array}{l}n \text { or } \\
\text { Mean }\end{array}$ & $\begin{array}{l}\text { Column } \\
\% \text { or SD }\end{array}$ & $\begin{array}{c}n \text { or } \\
\text { Mean }\end{array}$ & $\begin{array}{l}\text { Column } \\
\% \text { or SD }\end{array}$ & $\begin{array}{l}n \text { or } \\
\text { Mean }\end{array}$ & $\begin{array}{l}\text { Column } \\
\% \text { or SD }\end{array}$ \\
\hline \multicolumn{13}{|l|}{ Gender ( $n$ 4769) } \\
\hline Female & 21870 & 46.8 & 3344 & $70 \cdot 1$ & 672 & 73.0 & 557 & 73.1 & 783 & 73.1 & 1332 & $66 \cdot 1$ \\
\hline Male & 24838 & 53.2 & 1425 & 29.9 & 249 & 27.0 & 205 & $26 \cdot 9$ & 288 & $26 \cdot 9$ & 683 & 33.9 \\
\hline \multicolumn{13}{|l|}{ Race (n 4713) } \\
\hline Asian & 1256 & $2 \cdot 7$ & 291 & $6 \cdot 2$ & 35 & 3.8 & 43 & 3.8 & 62 & 5.9 & 151 & 7.6 \\
\hline $\begin{array}{c}\text { Black or African } \\
\text { American }\end{array}$ & 3822 & $8 \cdot 2$ & 270 & $5 \cdot 7$ & 99 & $10 \cdot 8$ & 57 & $7 \cdot 6$ & 48 & 4.6 & 66 & 3.3 \\
\hline White & 35770 & $76 \cdot 6$ & 3835 & 81.4 & 708 & $77 \cdot 2$ & 609 & $81 \cdot 1$ & 866 & $82 \cdot 3$ & 1652 & $82 \cdot 9$ \\
\hline Other & 2641 & $5 \cdot 7$ & 130 & $2 \cdot 8$ & 23 & $2 \cdot 5$ & 16 & $2 \cdot 1$ & 36 & $3 \cdot 4$ & 55 & $2 \cdot 8$ \\
\hline Two or moret & 1426 & $3 \cdot 1$ & 187 & 4.0 & 52 & $5 \cdot 7$ & 26 & 3.5 & 40 & $3 \cdot 8$ & 69 & 3.5 \\
\hline \multicolumn{13}{|l|}{ Ethnicity ( $n$ 4719) } \\
\hline Hispanic or Latino & 1793 & 3.8 & 220 & 4.7 & 52 & 5.7 & 38 & $5 \cdot 1$ & 61 & $5 \cdot 8$ & 69 & 3.5 \\
\hline $\begin{array}{l}\text { Not Hispanic or } \\
\text { Latino }\end{array}$ & 44915 & $96 \cdot 6$ & 4499 & $95 \cdot 3$ & 868 & $94 \cdot 3$ & 714 & 94.9 & 991 & $94 \cdot 2$ & 1926 & 96.5 \\
\hline $\begin{array}{l}\text { Age (years), mean } \\
\quad \text { and SD ( } n \text { 4785) }\end{array}$ & \multicolumn{2}{|c|}{$\begin{array}{l}\text { Data not } \\
\text { available }\end{array}$} & 23.62 & $6 \cdot 7$ & 22.92 & $5 \cdot 3$ & $22 \cdot 91$ & $5 \cdot 7$ & $23 \cdot 30$ & $6 \cdot 2$ & 24.4 & $7 \cdot 6$ \\
\hline \multicolumn{13}{|c|}{ Self-reported GPA $\ddagger$ ( $n$ 4576) } \\
\hline$<3.00$ & \multirow{4}{*}{\multicolumn{2}{|c|}{ Data not available }} & 748 & $16 \cdot 3$ & 265 & 29.5 & 148 & $20 \cdot 5$ & 137 & $13 \cdot 4$ & 198 & $10 \cdot 2$ \\
\hline $3.00-3.49$ & & & 1234 & $27 \cdot 0$ & 293 & $32 \cdot 6$ & 204 & $28 \cdot 3$ & 273 & $26 \cdot 8$ & 464 & $24 \cdot 0$ \\
\hline $3.50-3.84$ & & & 1440 & 31.5 & 213 & 23.7 & 241 & 33.4 & 338 & 33.1 & 648 & 33.5 \\
\hline $3.85-4.00$ & & & 1154 & $25 \cdot 2$ & 128 & $14 \cdot 2$ & 129 & $17 \cdot 9$ & 272 & $26 \cdot 7$ & 625 & $32 \cdot 3$ \\
\hline \multicolumn{13}{|c|}{ Year in school§ ( $n$ 4690) } \\
\hline Sophomore & 8043 & $17 \cdot 2$ & 1035 & $22 \cdot 1$ & 209 & $22 \cdot 8$ & 175 & $23 \cdot 3$ & 237 & $22 \cdot 6$ & 414 & 20.9 \\
\hline Junior & 8661 & 18.5 & 1176 & $25 \cdot 1$ & 260 & 28.4 & 196 & $26 \cdot 1$ & 262 & 25.0 & 458 & 23.2 \\
\hline Senior & 10792 & $23 \cdot 1$ & 1164 & $24 \cdot 8$ & 296 & $32 \cdot 3$ & 201 & $26 \cdot 8$ & 245 & 23.4 & 422 & 21.3 \\
\hline Graduate & 7857 & $16 \cdot 8$ & 1315 & 28.0 & 150 & $16 \cdot 4$ & 178 & 23.7 & 304 & 29.0 & 683 & 34.5 \\
\hline \multicolumn{13}{|c|}{ Enrolment status ( $n$ 4727) } \\
\hline Part-time & 7309 & $15 \cdot 6$ & 425 & $9 \cdot 0$ & 63 & $6 \cdot 8$ & 52 & 6.9 & 105 & $10 \cdot 0$ & 205 & $10 \cdot 3$ \\
\hline Full-time & 39399 & $84 \cdot 4$ & 4302 & 91.0 & 861 & 93.2 & 700 & $93 \cdot 1$ & 948 & $90 \cdot 0$ & 1793 & 89.7 \\
\hline
\end{tabular}

*Data from Fall 2017 enrolment period ${ }^{(31-33)}$; certain variables (mean age, self-reported GPA) could not be calculated based on how the data are provided from the universities within this university system.

†Two or more races refers to anyone who may identify with more than one race.

$\ddagger$ Self-reported GPA is self-reported grade point average.

$\S$ Sophomore, junior and senior are all classifications for undergraduate students based upon completed academic hours. Typically, sophomore standing is the equivalent to the second year of university, junior the third year, and senior the fourth and final year of university.

Contrary to one study in a state in the Southeast region where the food insecurity rates among college students were lower than the state average ${ }^{(12)}$, the present study found a food insecurity rate much higher than the regional average, which was similar to another study in the Southeast region ${ }^{(20)}$.

Results from the multivariate regression analyses indicated that students who were food insecure before entering college were nearly five times more likely to be food insecure in college when controlling for all other variables. This is the strongest factor that was identified in our analyses and is highly novel, as we are not aware of other studies that have examined previous food insecurity. These findings indicate that some of the high rates of food insecurity among college students could persist from food insecurity among students prior to college entry. Given that this may be first time that previous food insecurity has been explored in this population, additional research is needed to confirm these findings. Students with a lower self-reported GPA $(<3.85)$ were significantly more likely to be food insecure than students in the highest self-reported
GPA range (3.85-4.00), which is consistent with the literature $^{(18,19)}$.

Results from the multivariate analyses showed that undergraduate seniors were significantly more likely to be food insecure compared with graduate students. This relationship was not statistically significant, however, when comparing undergraduate sophomores or juniors with the reference group of graduate students. These findings identified a similar relationship to other studies with undergraduate students at increased risk for food insecurity compared with graduate students ${ }^{(17,20)}$.

Similar to another study ${ }^{(21)}$, students in the present study had a decreased likelihood of food insecurity when they received familial financial support, indicating a potential relationship between independence from familial financial support and food insecurity. Students in our sample who received loans that required repayment were more likely to be classified as food insecure, which supports similar findings in another study ${ }^{(18)}$. Conversely, students who received scholarships that did not require repayment were more likely to be food secure. 
Table 2 Bivariate analyses of food security status with demographic, financial and academic factors ${ }^{\star}$ among college students at a large public university system in the Southeast USA ( $n$ 4842), 2017

\begin{tabular}{|c|c|c|c|c|c|c|c|c|c|c|c|c|}
\hline \multirow[b]{2}{*}{ Variable } & \multicolumn{2}{|c|}{ Total sample } & \multicolumn{2}{|c|}{$\begin{array}{l}\text { Very low food } \\
\text { security }\end{array}$} & \multicolumn{2}{|c|}{ Low food security } & \multicolumn{2}{|c|}{$\begin{array}{l}\text { Marginal food } \\
\text { security }\end{array}$} & \multicolumn{2}{|c|}{ High food security } & \multirow[b]{2}{*}{$x^{2}$} & \multirow[b]{2}{*}{$P$ value } \\
\hline & $\begin{array}{l}n \text { or } \\
\text { Mean }\end{array}$ & $\begin{array}{l}\% \text { or } \\
\text { SD }\end{array}$ & $\begin{array}{l}n \text { or } \\
\text { Mean }\end{array}$ & $\begin{array}{c}\% \text { or } \\
\text { SD }\end{array}$ & $\begin{array}{c}n \text { or } \\
\text { Mean }\end{array}$ & $\begin{array}{c}\% \text { or } \\
\text { SD }\end{array}$ & $\begin{array}{c}n \text { or } \\
\text { Mean }\end{array}$ & $\begin{array}{c}\% \text { or } \\
\text { SD }\end{array}$ & $\begin{array}{c}n \text { or } \\
\text { Mean }\end{array}$ & $\begin{array}{l}\% \text { or } \\
\text { SD }\end{array}$ & & \\
\hline \multicolumn{13}{|c|}{ Food insecure before college } \\
\hline Yes & 921 & $19 \cdot 9$ & 413 & $45 \cdot 4$ & 220 & $30 \cdot 1$ & 172 & $16 \cdot 8$ & 116 & $5 \cdot 9$ & \multirow[t]{2}{*}{$665 \cdot 82$} & \multirow[t]{2}{*}{$<0.001$} \\
\hline No & 3710 & $80 \cdot 1$ & 497 & $54 \cdot 6$ & 512 & $69 \cdot 9$ & 854 & $83 \cdot 2$ & 1847 & $94 \cdot 1$ & & \\
\hline \multicolumn{13}{|l|}{ Familial financial support } \\
\hline Yes & 3016 & $64 \cdot 8$ & 475 & $52 \cdot 1$ & 486 & $65 \cdot 8$ & 690 & $66 \cdot 7$ & 1365 & $69 \cdot 4$ & \multirow[t]{2}{*}{83.97} & \multirow[t]{2}{*}{$<0.001$} \\
\hline No & 1636 & $35 \cdot 2$ & 436 & $47 \cdot 9$ & 253 & $34 \cdot 2$ & 344 & $33 \cdot 3$ & 603 & $30 \cdot 6$ & & \\
\hline \multicolumn{13}{|l|}{ Part-time job } \\
\hline Yes & 2393 & 51.4 & 556 & $61 \cdot 0$ & 410 & 55.5 & 544 & $52 \cdot 6$ & 883 & 44.9 & \multirow[t]{2}{*}{$72 \cdot 98$} & \multirow[t]{2}{*}{$<0.001$} \\
\hline No & 2259 & $48 \cdot 6$ & 355 & $39 \cdot 0$ & 329 & 44.5 & 490 & 47.4 & 1085 & $55 \cdot 1$ & & \\
\hline \multicolumn{13}{|l|}{ Full-time job } \\
\hline Yes & 617 & $13 \cdot 3$ & 108 & 11.9 & 66 & 8.9 & 120 & $11 \cdot 6$ & 323 & $16 \cdot 4$ & \multirow[t]{2}{*}{33.07} & \multirow[t]{2}{*}{$<0.001$} \\
\hline No & 4035 & $86 \cdot 7$ & 803 & $88 \cdot 1$ & 673 & $91 \cdot 1$ & 914 & $88 \cdot 4$ & 1645 & $83 \cdot 6$ & & \\
\hline \multicolumn{13}{|c|}{ Using personal savings for income } \\
\hline Yes & 1801 & 38.7 & 304 & 33.4 & 280 & 37.9 & 437 & $42 \cdot 3$ & 780 & 39.6 & \multirow{2}{*}{$17 \cdot 37$} & \multirow[t]{2}{*}{0.001} \\
\hline No & 2851 & $61 \cdot 3$ & 607 & $66 \cdot 6$ & 459 & $62 \cdot 1$ & 597 & $57 \cdot 7$ & 1188 & $60 \cdot 4$ & & \\
\hline \multicolumn{13}{|c|}{ Receiving loans requiring repayment } \\
\hline Yes & 1394 & $30 \cdot 0$ & 371 & $40 \cdot 7$ & 276 & $37 \cdot 3$ & 317 & $30 \cdot 7$ & 430 & $21 \cdot 8$ & 131.44 & $<0.001$ \\
\hline No & 3258 & $70 \cdot 0$ & 540 & $59 \cdot 3$ & 463 & $62 \cdot 7$ & 717 & $69 \cdot 3$ & 1538 & $78 \cdot 2$ & & \\
\hline Participation in a meal & & & & & & & & & & & & \\
\hline Yes & 1346 & $29 \cdot 1$ & 282 & $31 \cdot 0$ & 241 & $33 \cdot 0$ & 314 & $30 \cdot 6$ & 509 & $25 \cdot 9$ & $17 \cdot 49$ & 0.001 \\
\hline No & 3283 & $70 \cdot 9$ & 628 & $69 \cdot 0$ & 490 & $67 \cdot 0$ & 712 & $69 \cdot 4$ & 1453 & $74 \cdot 1$ & & \\
\hline Receiving scholarships & requiri & repaym & & & & & & & & & & \\
\hline Yes & 2162 & $46 \cdot 5$ & 382 & 41.9 & 348 & $47 \cdot 1$ & 499 & $48 \cdot 3$ & 933 & $47 \cdot 4$ & $9 \cdot 68$ & 0.021 \\
\hline No & 2490 & 53.5 & 529 & $58 \cdot 1$ & 391 & 52.9 & 535 & $51 \cdot 7$ & 1035 & $52 \cdot 6$ & & \\
\hline Year in school & & & & & & & & & & & & \\
\hline Sophomore & 1035 & $22 \cdot 1$ & 209 & $22 \cdot 8$ & 175 & $23 \cdot 3$ & 237 & $22 \cdot 6$ & 414 & $20 \cdot 9$ & $121 \cdot 34$ & $<0.001$ \\
\hline Junior & 1176 & $25 \cdot 1$ & 260 & $28 \cdot 4$ & 196 & $26 \cdot 1$ & 262 & $25 \cdot 0$ & 458 & $23 \cdot 2$ & & \\
\hline Senior & 1164 & $24 \cdot 8$ & 296 & $32 \cdot 3$ & 201 & $26 \cdot 8$ & 245 & 23.4 & 422 & $21 \cdot 3$ & & \\
\hline Graduate & 1315 & $28 \cdot 0$ & 150 & $16 \cdot 4$ & 178 & 23.7 & 304 & $29 \cdot 0$ & 683 & 34.5 & & \\
\hline Self-reported GPA† & & & & & & & & & & & & \\
\hline$<3.00$ & 748 & $16 \cdot 3$ & 265 & 29.5 & 148 & $20 \cdot 5$ & 137 & $13 \cdot 4$ & 198 & $10 \cdot 2$ & $288 \cdot 70$ & $<0.001$ \\
\hline $3.00-3.49$ & 1234 & $27 \cdot 0$ & 293 & $32 \cdot 6$ & 204 & $28 \cdot 3$ & 273 & $26 \cdot 8$ & 464 & $24 \cdot 0$ & & \\
\hline $3.50-3.84$ & 1440 & 31.5 & 213 & 23.7 & 241 & 33.4 & 338 & $33 \cdot 1$ & 648 & 33.5 & & \\
\hline $3.85-4.00$ & 1154 & $25 \cdot 2$ & 128 & $14 \cdot 2$ & 129 & $17 \cdot 9$ & 272 & $26 \cdot 7$ & 625 & $32 \cdot 3$ & & \\
\hline Essential expenditures & 7.75 & 3.9 & $7 \cdot 62^{\mathrm{a}}$ & 3.5 & $7 \cdot 27^{\mathrm{a}}$ & 3.6 & $7 \cdot 56^{\mathrm{a}}$ & $3 \cdot 7$ & $8.09^{\mathrm{b}}$ & $4 \cdot 2$ & - & $<0.001$ \\
\hline $\begin{array}{l}\text { Non-essential } \\
\text { expenditures }\end{array}$ & 3.99 & $2 \cdot 4$ & $2 \cdot 96^{a}$ & 1.9 & $3 \cdot 77^{\mathrm{b}}$ & $2 \cdot 1$ & $4 \cdot 01^{b}$ & $2 \cdot 2$ & $4.55^{\mathrm{c}}$ & $2 \cdot 6$ & - & $<0.001$ \\
\hline
\end{tabular}

Essential expenditures include monthly expenditures on housing, groceries, transportation and cell phones; non-essential expenditures include monthly expenditures on shopping, entertainment and eating out.

a,b,c Mean values within a row with unlike superscript letters were significantly different (Tukey post hoc test): $P<0.01$.

*Values are $n$ and \% for $x^{2}$ analyses or means and SD for ANOVA (essential expenditures; non-essential expenditures).

†Self-reported GPA is self-reported grade point average.

Additionally, students who were employed part-time were significantly more likely to be food insecure than students who were not employed part-time. Students with full-time employment were less likely to be food insecure than students who were not employed full-time. Contrary to one study ${ }^{(16)}$, as students in our study increased spending on non-essential items (including eating out, shopping and entertainment), they had a significantly lower probability of food insecurity. This may mean that students who were food secure had more disposable income that allowed them to make such expenditures, as they may have had support from parents or guardians to pay for all their essential needs. However, since this is inconsistent with previous studies, the relationship between spending habits and food insecurity status should continue to be studied. As students increased spending on essential items (including housing, large expenses, transportation, cell phones and groceries), they had a small but statistically significant increase in the likelihood of food insecurity.

\section{Strengths and limitations}

A strength of the present study is its novelty; it is the first study that the authors are aware of to assess previous food insecurity prior to coming to college. Additionally, this research fills an important gap in identifying food insecurity prevalence among college students in the Southeast USA as the results of other studies are inconsistent ${ }^{(12,20)}$. Within the survey, the use of the AFSSM contributes to the strength of the research, as the AFSSM is considered the gold standard for measuring food security status among $\operatorname{adults}^{(28)}$. 
Table 3 Multivariate logistic regression of factors associated with food insecurity among college students at a large public university system in the Southeast USA, 2017

\begin{tabular}{|c|c|c|c|c|}
\hline Variable (reference category ${ }^{\star}$ ) & $B$ & $P$ value & OR & $95 \% \mathrm{Cl}$ \\
\hline \multicolumn{5}{|l|}{ Familial financial support (yes) } \\
\hline No & 0.45 & $<0.001$ & 1.56 & $1.33,1.84$ \\
\hline \multicolumn{5}{|l|}{ Loans requiring repayment (no) } \\
\hline Yes & 0.35 & $<0.001$ & 1.42 & $1 \cdot 22,1 \cdot 66$ \\
\hline \multicolumn{5}{|c|}{ Scholarships not requiring repayment (yes) } \\
\hline No & 0.18 & 0.018 & $1 \cdot 20$ & 1.0 \\
\hline \multicolumn{5}{|l|}{ Part-time job (no) } \\
\hline Yes & 0.25 & 001 & $1 \cdot 28$ & $1 \cdot 10$ \\
\hline \multicolumn{5}{|l|}{ Full-time job (yes) } \\
\hline No & 0.26 & 0.049 & $1 \cdot 30$ & $1.00,1.69$ \\
\hline \multicolumn{5}{|l|}{ Personal savings (yes) } \\
\hline No & $0 \cdot 19$ & 014 & 1.21 & 1.0 \\
\hline \multicolumn{5}{|l|}{ Participation in a meal plan (no) } \\
\hline Yes & 0.08 & 28 & 1.09 & 0.9 \\
\hline \multicolumn{5}{|l|}{ Year in school (graduate) } \\
\hline Sophomore & 0 & 99 & $1 \cdot 15$ & \\
\hline & 0 & & 1.24 & 0. \\
\hline Senior & 0.35 & 4 & 1.41 & $1 \cdot 1$ \\
\hline \multicolumn{5}{|l|}{ Food insecure before college (no) } \\
\hline Yes & 1.57 & $<0.001$ & $4 \cdot 78$ & $4 \cdot 00,5$ \\
\hline \multicolumn{5}{|l|}{ Self-reported GPA (3.85-4.00)† } \\
\hline$<3.00$ & 1.05 & $<0.001$ & $2 \cdot 85$ & $2 \cdot 2$ \\
\hline $3 \cdot 00-3$ & 0.62 & $<0.001$ & 1.85 & $1.49,2.29$ \\
\hline $3 \cdot 50-3$ & 0.34 & 0.001 & 1.41 & $1.15,1.73$ \\
\hline Essential & 0.03 & 0.033 & 1.03 & $1.00,1.05$ \\
\hline Non-essential expendituresł & -0.17 & $<0.001$ & 0.84 & $0.81,0.87$ \\
\hline
\end{tabular}

Total sample $=4385$, participants with missing data were dropped from the analysis.

Adjusted for campus attended, gender, race, ethnicity and age. $a, P \leq 0.05$ ${ }^{*}$ Reference category included for categorical variables. †Self-reported GPA is self-reported grade point average.

‡Essential includes monthly expenditures on housing, groceries, transportation and cell phones; non-essential includes monthly expenditures on shopping, entertainment and eating out.

One limitation of the study was the cross-sectional design, inhibiting causal inferences to be deduced from the findings. Additional research is needed, particularly including intervention trials, to address food insecurity among college students. Since the study used a selfreported survey technique to collect data, recall and social desirability biases could be present in the results. This limitation is consistent with limitations in published research assessing food insecurity among college students $^{(12-14,16-19,23)}$. The response rate of our study is $12.5 \%$, which is a relatively small percentage of the overall university system population; however, this response rate is much higher than other similar studies that had response rates of $3 \cdot 8-7 \cdot 0 \%{ }^{(17-19)}$. Additionally, the sample was nonrandom and may not be representative of the university system overall, resulting in selection bias. For example, there was a high percentage of female respondents $(70 \cdot 1 \%)$ among the sample population, which is more than the percentage of the overall university system (46.8\%). When completing regression analyses, 9\% of the final sample was dropped due to missing responses; while this is a high percentage and an important limitation of the study, the overall sample size was still appropriate for these analyses. Lastly, the results may be biased as students with financial strains may have been more likely to participate in the survey in hope of winning the drawing for one of the \$US 100 gift cards.

\section{Conclusions}

Overall, the students across this large public university system in the Southeast USA had high rates of food insecurity (35.6\%). These findings support similar findings at other universities, with an average food insecurity rate of $42 \%$ among college students ${ }^{(22)}$. Future research is needed to further explore the relationship between food security status during college and previous food insecurity to determine what factors in the college setting may be exacerbating pre-existing food insecurity. As this relationship has been newly discovered, it may be beneficial to screen for food security status during the financial aid review process to identify students who may need additional support or resources to successfully complete their studies. Additionally, future research is needed to define the multiple dimensions of socioeconomic effects on food security status, particularly among the college students who may have varying sources of support that can be difficult to measure. As predictors associated with food insecurity are being established, future studies should explore interventions, programming and policies that can influence those factors to help reduce food insecurity rates.

\section{Acknowledgements}

Acknowledgements: This research was conducted in partnership with the Southeastern Universities Consortium on Hunger Poverty and Nutrition. The authors would like to acknowledge Deidre White, John Abel, Phil Showalter and Sally Badoud for their support of this project and their assistance in the dissemination of the survey at the corresponding campuses. They would also like to thank the student participants who were willing to share their information as part of this survey. Financial support: This research received no specific grant from any funding agency in the public, commercial or not-for-profit sectors. Conflict of interest: None. Authorship: R.W. was responsible for the designing and implementing the study; collecting, managing and analysing the data; and drafting the manuscript. M.S. was responsible for providing significant input on study design and survey content development; and was actively engaged in manuscript drafting and review and dissemination of results to relevant stakeholders. S.C. provided significant input on study design and survey content; and gave significant feedback on manuscript drafts. E.A.S. provided direct oversight of and input on the study and survey design; oversaw data collection, cleaning and analysis; aided in the manuscript 
development, drafting and revision process; and also serves as the corresponding author for this manuscript. Etbics of buman subject participation: This study was conducted according to the guidelines laid down in the Declaration of Helsinki and all procedures involving human subjects were approved by the University of Tennessee, Knoxville Institutional Review Board. Written informed consent was obtained from all subjects.

\section{References}

1. Coleman-Jensen A, Rabbitt, Matthew P et al. (2017) Household Food Security in the United States in 2016. Economic Research Report no. ERR-237. Washington, DC: US Department of Agriculture, Economic Research Service.

2. Adams EJ, Grummer-Strawn L \& Chavez G (2003) Food insecurity is associated with increased risk of obesity in California women. J Nutr 133, 1070-1074.

3. Townsend MS, Peerson J, Love B et al. (2001) Food insecurity is positively related to overweight in women. $J$ Nutr 131, 1738-1745.

4. Nord M \& Prell M (2017) Struggling to feed the family: What does it mean to be food insecure? Amber Waves. https:// www.ers.usda.gov/amber-waves/2007/june/struggling-tofeed-the-family-what-does-it-mean-to-be-food-insecure/ (accessed November 2017).

5. Jyoti DF, Frongillo EA \& Jones SJ (2005) Food insecurity affects school children's academic performance, weight gain, and social skills. J Nutr 135, 2831-2839.

6. Kleinman RE, Murphy JM, Little M et al. (1998) Hunger in children in the United States: potential behavioral and emotional correlates. Pediatrics 101, e3.

7. Rose D (1999) Economic determinants and dietary consequences of food insecurity in the United States. $J$ Nutr 129, 2 S Suppl., 517-520.

8. Cason KL \& Wenrich TR (2002) Health and nutrition beliefs, attitudes, and practices of undergraduate college students: a needs assessment. Top Clin Nutr 17, 52-70.

9. Greaney ML, Less FD, White AA et al. (2009) College students' barriers and enablers for healthful weight management: a qualitative study. J Nutr Educ Behav 41, 281-286.

10. Pancer SM, Hunsberger B, Pratt MW et al. (2000) Cognitive complexity of expectations and adjustment to university in the first year. J Adolesc Res 15, 38-57.

11. US Department of Education, National Center for Education Statistics (2018) Digest of Education Statistics, 2016. Chapter 3: Postsecondary education. https://nces.ed.gov/programs/ digest/d16/ch_3.asp (accessed November 2017).

12. Gaines A, Robb CA, Knol LL et al. (2014) Examining the role of financial factors, resources and skills in predicting food security status among college students. Int J Consum Stud 38, 374-384.

13. Maroto ME, Snelling A \& Linck H (2015) Food insecurity among community college students: prevalence and association with grade point average. Community Coll J Res Pract 39, 515-526.

14. Bruening M, Brennhofer S, van Woerden I et al. (2016) Factors related to the high rates of food insecurity among diverse, urban college freshmen. J Acad Nutr Diet 116, 1450-1457.

15. Bruening M, van Woerden I, Todd M et al. (2018) Hungry to learn: the prevalence and effects of food insecurity on health behaviors and outcomes over time among a diverse sample of university freshmen. Int J Behav Nutr Phys Act 15, 9.

16. Chaparro MP, Zaghloul SS, Holck P et al. (2009) Food insecurity prevalence among college students at the
University of Hawai'i at Manoa. Public Health Nutr 12, 2097-2103.

17. Mirabitur E, Peterson KE, Rathz C et al. (2016) Predictors of college-student food security and fruit and vegetable intake differ by housing type. J Am Coll Health 64 , $555-564$

18. Morris LM, Smith S, Davis J et al. (2016) The prevalence of food security and insecurity among Illinois university students. J Nutr Educ Behav 48, 376-382.e1.

19. Patton-Lopez MM, Lopez-Cevallos DF, Cancel-Tirado DI et al. (2014) Prevalence and correlates of food insecurity among students attending a midsize rural university in Oregon. J Nutr Educ Behav 46, 209-214.

20. McArthur LH, Ball L, Danek AC et al. (2018) A high prevalence of food insecurity among university students in Appalachia reflects a need for educational interventions and policy advocacy. J Nutr Educ Behav 50, 564-572.

21. Payne-Sturges DC, Tjaden A, Caldeira KM et al. (2018) Student hunger on campus: food insecurity among college students and implications for academic institutions. Am J Health Promot 32, 349-354.

22. Bruening M, Argo K, Payne-Sturges D et al. (2017) The struggle is real: a systematic review of food insecurity on postsecondary education campuses. J Acad Nutr Diet 117, $1767-1791$.

23. Thomas S (2004) Using Web and Paper Questionnaires for Data-Based Decision Making. Thousand Oaks, CA: SAGE Publications, Inc.

24. Lin M-T, Peters RJ Jr, Ford K et al. (2013) The relationship between perceived psychological distress, behavioral indicators and African-American female college student food insecurity. Am J Health Stud 28, 127.

25. The University of Tennessee (2017) Annual Report to the General Assembly 2017. http://president.tennessee.edu/ static/annual-report/2017/2017-annual-report-pages.pdf (accessed December 2018).

26. Trespalacios JH \& Perkins RA (2016) Effects of personalization and invitation email length on web-based survey response rates. TechTrends $\mathbf{6 0}, 330-335$.

27. Hager ER, Quigg AM, Black MM et al. (2010) Development and validity of a 2 -item screen to identify families at risk for food insecurity. Pediatrics 126, e26-e32.

28. US Department of Agriculture, Food and Nutrition Service (2013) Guide to measuring household food security (revised 2000). http://www.fns.usda.gov/guide-measuringhousehold-food-security-revised-2000 (accessed November 2016).

29. Irony T, Li Caiyan \& Silverman P (2012) Statistical methods in clinical trials. In Statistical Methods in Healthcare, 1st ed., pp. 38-39 [F Faltin, R Kennett and F Ruggeri, editors]. Chichester: John Wiley \& Sons.

30. Stommel MP \& Stommel M (2014) Statistics for Advanced Practice Nurses and Health Professionals, 1st ed. New York: Springer Publishing Company.

31. The University of Tennessee, Martin (2018) Statistical reports. https://www.utm.edu/departments/irp/statistical_reports.php (accessed September 2018).

32. The University of Tennessee, Chattanooga, Office of Planning, Evaluation, and Institutional Research (2018) Factbook tables. https://www.utc.edu/planning-evaluationinstitutional-research/factbook/index.php (accessed September 2018).

33. The University of Tennessee, Knoxville, Office of Institutional Research and Assessment (2018) Enrollment data: 2017-2018. https://oira.utk.edu/reporting/fact-book/ (accessed September 2018). 